\title{
Correspondance
}

\section{Money and medical education}

Tapplaud Farrah Mateen ${ }^{1}$ for criItiquing, among other things, the money-paved road to medical school. Fees for my med school applications this year exceeded $\$ 1000$. If I receive interviews for any of these applications, I will dry-clean my suit, take time off work, drop money for a flight, hotel, and food, and respond to questions about my lack of hobbies (sorry - I have 3 jobs and need to study frenetically because only those with the top 400 GPAs are considered). What makes the process so difficult isn't the money itself, but the fact that it is entirely a gamble. I can expend my life savings, work half a dozen jobs, study until my brain will absorb no more. I can live in a slum so that I can afford to write the MCATs, yet I would never have gotten interviews if another (wealthy) student hadn't generously lent me the (shockingly expensive) sample MCATs she bought off the Internet. I will trek to any of the 4 corners of this country if I'm blessed enough to receive a one-time 45minute period of scrutiny (curiously, to work the line at a Toyota plant, there are no fewer than 5 interviews), but there's no guarantee that I won't just be left with large bills and no certain way of paying them off. Would the interviewers like to hear how I spent 72 hours a week in the summer mowing lawns, developing sunstroke (and potentially skin cancer) in the process, and was thrilled to get back to school because it involved sitting and only 20 hours a week of mowing? It's a truly fascinating story. What it isn't is a recipe for getting into medical school.

\section{Warren Michalski \\ London, Ont.}

\section{Reference}

1. Mateen F. Darwinian pursuits with interruptions by Huxley: a brief pontification on medical education. CMA7 2004;171(12):1466-8.

DOI:10.1503/cmaj.1050028

\section{Beyond mythology}

A s quoted by Loreen Pindera, ${ }^{1}$ SenAator Michael Kirby is right that it is a "great myth of Canadian public life" that the Canada Health Act prohibits private delivery of health services.

Having worked in the United Kingdom (and now returning to Canada), I may have some relevant observations. The UK's National Health Service (NHS) is embracing Kirby's "provider agnosticism," making the NHS more an organizing principle than a stateowned and run health service.

New private NHS providers (including some from Canada) have targeted areas where clinical procedures can be done quickly and efficiently and where patient demand is high (and waiting times long) at prices the Department of Health is prepared to afford.

A key emerging lesson for Canada can be found in the UK priority on "public choice" and provider plurality in providing public services, which gives users greater choice in how and when they access these services - thus focusing on what the citizen-user wants, not what the service providers want. This "disruptive" idea will reshape services in the image of higher public acceptability and quality not otherwise obtainable through heavyhanded methods. It is hard to imagine a system without such incentives being worth funding in the first place.

That there is a whole Europe full of countries with high standards of care delivered in complex combinations of public and private ownership should make critics of private providers pause to reflect on the certainty of their position. The opportunities to improve health care for Canadians through a more flexible and open system will be lost unless we can move beyond the myths. Reform starts with understanding reality, not hiding from it.

\section{Michel Tremblay}

Tremblay Consulting

Smarden, Kent, UK

(moving back to Canada in June 2005)

\author{
Reference \\ 1. Pindera L. Increasing private delivery of publicly \\ funded services? CMA7 2005;172(2):167.
}

Competing interests: Dr. Tremblay conducts policy research and consultancy for governments and private companies in the health sector.

DOI:10.1503/cmaj.1050033

\section{Kappa statistic}

Twould like to thank CMAf and the Evidence-Based Medicine Teaching Tips Working Group for the teaching tips series, which is wonderfully useful to those of us who are teaching these basic concepts to residents and other physicians. Part 3 in the series, discussing the kappa statistic, ${ }^{1}$ contained a couple of points to which I would like to contribute, on the basis of my own teaching experiences.

Whereas Thomas McGinn and associates $^{1}$ suggest that students construct $2 \times 2$ tables and calculate kappa from successively higher rates of positive calls (see tip 3 in the article), I have instead given students the raw data from actual small studies (with fewer than 25 subjects) and then asked them to construct the $2 \times 2$ table and calculate actual agreement and chance agreement using the multiplication rule. ${ }^{2}$ The multiplication rule can be used to calculate joint probability if 2 different events are independent of one another. Most situations that consumers of the medical literature will encounter involve analyzing the numbers provided in various data forms and then determining whether the level of agreement is both acceptable and consistent with the data presented. Rarely will readers need to assign a level of agreement and calculate the kappa statistic. Therefore, the method described here might be valuable as another means to calculate chance agreement and kappa on the basis of more realistic values.

For example, our institution recently implemented the emergency severity index ${ }^{3}$ (ESI) for nursing triage. Given a random sample of 25 patients 
from month 1 after implementation and using the nurse administrator's ESI score as the second assessment, I asked residents to compare high-risk and lower-risk triage scores between the triage nurse and the nurse administrator. The resulting $2 \times 2$ table is completed as shown in Fig. 1, and calculation of chance agreement proceeds as follows:

kappa $=[($ observed agreement expected agreement $) /(1$ - expected agreement)]

High-risk assessments by nurse administrator: $11 / 25=0.44$

High-risk assessments by triage nurse: $10 / 25=0.40$

Lower-risk assessments by nurse administrator: $14 / 25=0.56$

Lower-risk assessments by triage nurse: $15 / 25=0.60$

Observed agreement $=(9+13) / 25=$ 0.88

Expected agreement $=$ (chance of highrisk assessment) + (chance of lower-risk assessment)

Chance of high-risk assessment $=0.44$ $\times 0.40=0.176$

Chance of lower-risk assessment $=0.56$ $\times 0.60=0.336$

Expected agreement by chance alone $=$ $0.176+0.336=0.512$

kappa $=(0.88-0.512) /(1-0.512)=$ $0.368 / 0.488=0.75$

Table 1 in both the teachers' ${ }^{1}$ and learners' ${ }^{4}$ versions of this article references Maclure and Willett ${ }^{5}$ as a source of the qualitative classification of kappa. My own review of that paper did not reveal any attempt to qualitatively assess kappa, but at least 3 other sources have done so. ${ }^{6-8}$ In my experience the most widely used classification for kappa is the last of these, ${ }^{8}$ which proposed the guidelines for interpreting kappa values as outlined in Table 1 in this letter.

\section{Christopher R. Carpenter}

Assistant Professor

Division of Emergency Medicine

Washington University School

of Medicine

St. Louis, Mo.

\section{References}

1. McGinn T, Wyer PC, Newman TB, Keitz S, Leipzig R, Guyatt G, for Evidence-Based Medicine Teaching Tips Working Group. Tips for teachers of evidence-based medicine: 3 . Understanding and calculating kappa. CMA7 2004;171 (11):Online-1 to Online-9. Available: www.cmaj .ca/cgi/data/171/11/1369/DC1/1 (accessed 2005 Jan 10).

2. Dawson B, Trapp RG. Basic and clinical biostatistics. 3rd ed. New York: McGraw-Hill; 2001. p. 66-7, 115-7.

3. Wuerz RC, Milne LW, Eitel DR, Travers D, Gilboy N. Reliability and validity of a new fivelevel triage instrument. Acad Emerg Med 2000;7:236-42.

4. McGinn T, Wyer PC, Newman TB, Keitz S, Leipzig R, Guyatt G, for Evidence-Based Medicine Teaching Tips Working Group. Tips for learners of evidence-based medicine: 3. Measures of observer variability (kappa statistic). CMA7 2004;171(11):1369-73.

5. Maclure M, Willett WC. Misinterpretation and misuse of the kappa statistic. Am $\mathcal{F}$ Epidemiol 1987;126:161-9.

6. Altman DG. Practical statistics for medical students. London: Chapman and Hall; 1991.

7. Fleiss JL. Statistical methods for rates and proportions. 2nd ed. New York: John Wiley and Sons; 1981. p. 218.

8. Byrt T. How good is that agreement? [letter]. Epidemiology 1996;7:561.

DOI:10.1503/cmaj.1041742

$\mathrm{I}^{\mathrm{n}}$ their excellent overview of a common statistical measure of agreement, Thomas McGinn and colleagues ${ }^{1}$ suggest in Table 1 that values for the kappa statistic range from 0 to 1 . However, negative values of kappa are also possible. ${ }^{2}$ Although unusual in practice, a negative kappa statistic results when agreement occurs less often than predicted by chance alone. This may indicate genuine disagreement, or it may reflect a problem in the application of a diagnostic test. Readers and researchers who encounter a negative kappa statistic should be aware of its implications, rather than blaming mathematical or typographic errors or computer "gnomes."

\section{David N. Juurlink}

Sunnybrook and Women's College

Health Sciences Centre

Toronto, Ont.

Allan S. Detsky

Mount Sinai Hospital

Toronto, Ont.

\section{References}

1. McGinn T, Wyer PC, Newman TB, Keitz S, Leipzig R, Guyatt G, for Evidence-Based Medicine Teaching Tips Working Group. Tips for learners of evidence-based medicine: 3. Measures of observer variability (kappa statistic). CMA7 2004;171(11):1369-73.

2. Kramer MS, Feinstein AR. Clinical biostatistics. LIV. The biostatistics of concordance. Clin Pharmacol Ther 1981;29:111-23.

DOI:10.1503/cmaj.1041744

A $s$ a teacher of basic skills in evidence-based medicine (EBM), I have appreciated the CMAJ articles that have been appearing in the EBM "tips" series. In particular, I was happy to see the discussion of the kappa statistic, ${ }^{1}$ specifically the calculation of chance agreement (e.g., Table 3 in the article).

Unfortunately, discussions of kappa tend to focus on dichotomous variables, such as positive or negative results on mammography or the presence or absence of Murphy's sign. In cases of con-

\begin{tabular}{|c|c|c|c|c|}
\hline \multirow{5}{*}{$\begin{array}{l}\text { Nurse } \\
\text { administrator }\end{array}$} & \multirow{4}{*}{$\begin{array}{l}\text { High } \\
\text { risk } \\
\text { Lower } \\
\text { risk }\end{array}$} & \multicolumn{2}{|c|}{ Triage nurse } & \multirow[b]{2}{*}{ Total } \\
\hline & & $\begin{array}{l}\text { High } \\
\text { risk }\end{array}$ & $\begin{array}{l}\text { Lower } \\
\text { risk }\end{array}$ & \\
\hline & & 9 & 2 & 11 \\
\hline & & 1 & 13 & 14 \\
\hline & Total & 10 & 15 & 25 \\
\hline
\end{tabular}

Fig. 1: Agreement table for triage nurse and nurse administrator at the author's hospital, using the emergency severity index $^{3}$ for nursing triage.
Table 1: Qualitative classification of kappa values*

\begin{tabular}{lc}
\hline Kappa value & Degree of agreement \\
\hline$\leq 0$ & None \\
$0.01-0.20$ & Poor \\
$0.21-0.40$ & Slight \\
$0.41-0.60$ & Fair \\
$0.61-0.80$ & Good \\
$0.81-0.92$ & Very good \\
$0.93-1.00$ & Excellent
\end{tabular}

*Adapted, with permission of the publisher, from Byrt T. How good is that agreement? [letter]. Epidemiology 1996; 7:561 